\title{
Justicia comunitaria dentro la justicia ordinaria y su naturaleza en el resguardo de los derechos humanos
}

\section{Community justice within the ordinary justice and its nature in the protection of human rights}

\author{
Iván Gonzales Isidro \\ ivanlic@hotmail.es \\ Universidad Andina Simón Bolívar y Estudio Jurídico Gonzales \& Asociados, Bolivia
}

Recibido octubre 2018; arbitrado noviembre 2018; y publicado enero 2019

\section{RESUMEN}

La Justicia Comunitaria, tiene competencia para administrar justicia a través de sus autoridades, resolver conflictos o problemas en base a sus usos y costumbres, normas y procedimientos. El objetivo fue proponer la implementación de una norma que resguarde los derechos humanos de los Pueblos indígena originarios campesinos de Bolivia basado en el Convenio 169 sobre Pueblos Indígenas y Tribales. En el desarrollo de este estudio se usaron distintos métodos para el abordaje y tratamiento de las fuentes de información. El método inductivo permitió obtener de la experiencia específica de una o dos comunidades; también el deductivo, método histórico, método etnológico, método exegético, método de análisis y síntesis. Para finalizar existe la necesidad de implementar la justicia comunitaria dentro la justicia ordinaria sin necesidad de desvirtuar la naturaleza de los usos y costumbres de la justicia comunitaria en resguardo de los derechos humanos, ya que no se cuenta con un tratamiento adecuado, en la aplicación de las convenciones sobre derechos humanos.

Palabras clave: Justicia comunitaria; derechos humanos; indígenas; tribales
ABSTRACT

Community justice, has the competence to administer justice through its authorities, to resolve conflicts or problems based on its uses and customs, rules and procedures. The objective was to propose the implementation of a standard that safeguard the human rights of indigenous native peasants of Bolivia based on the Convention 169 on Indigenous and Tribal peoples. In the development of this study different methods were used for the approach and treatment of the sources of information. The inductive method allowed to obtain from the specific experience of one or two communities; also the deductive, historical method, Ethnological method, Exegetical method, method of analysis and synthesis. To conclude, there is a need to implement community justice within ordinary justice without the need to undermine the nature of the uses and customs of Community justice in the protection of human rights, since there is no appropriate treatment in the implementation of the human rights conventions.

Key words: Community justice; Human rights; Indigenous; Tribal 
INTRODUCCIÓN

El presente artículo de investigación, tiene como punto de partida de estudio a la Justicia Comunitaria su naturaleza, usos y costumbres, con relación a la Constitución Política del Estado Plurinacional de Bolivia, Tratados y Convenios Internacionales, especialmente en materia de derechos humanos que protege los derechos individuales en general, posteriormente se analizará como la Justicia Comunitaria entra a desarrollarse fuera de su ámbito jurisdiccional y a la vez complementa algunas tareas legales conjuntamente la Justicia Ordinaria.

Por lo que entremos a dar algunas pinceladas de la presente investigación, para darles una idea general cual la función de la Justicia Comunitaria dentro de las naciones indígenas originarias campesinas que es su ámbito de competencia y jurisdicción.

La Justicia Comunitaria, tiene competencia para administrar justicia a través de sus autoridades quienes resuelven conflictos o problemas en base a sus usos y costumbres, normas y procedimientos propios. Teniendo todo un sistema jurídico indígena originario campesino que logra resolver conflictos, problemas que nacen de las relaciones sociales o de la propia naturaleza vivida de una comunidad y que el Estado le da un espacio con un reconocimiento constitucional, que se traduce en respetar su forma de administrar justicia de conformidad con sus normas $y$ procedimiento propio, derecho propio con una igualdad de jerarquía en relación con la justicia ordinaria.

Sin embargo, la Constitución Política del Estado Plurinacional de Bolivia también le da límites al derecho indígena, es decir, el límite está dado por el pleno respeto de los derechos individuales y los derechos humanos, traduciendo en un control para que los limites expresados no sean vulnerados por las decisiones o resoluciones que emiten las autoridades indígenas al momento de resolver un conflicto dentro de la jurisdicción de la Justicia Comunitaria. A pesar que está dada la valla, para que no puedan vulnerar los derechos individuales en las resoluciones que emiten las autoridades indígenas para resolver un conflicto, no es suficiente o no garantiza su cumplimiento que establece la norma suprema, por lo que en muchos casos se ha tenido que acudir a la justicia ordinaria para denunciar que los actos jurídicos de la Justicia Comunitaria ha vulnerado los derechos fundamentales ya sean del infractor o de la víctima para que la misma sea reparada.

En Bolivia se encuentra bajo un pluralismo jurídico, es decir, que se ejerce a través de la jurisdicción indígena y la jurisdicción ordinaria, siendo un reflejo jurídico de la interculturalidad jurídica del país. Aclarando un poco, el pluralismo jurídico es la interacción de diferentes sistemas jurídicos en un mismo campo social que sobreviven complementándose mutuamente y desarrollándose conjuntamente, con la función de administrar justicia de conformidad con sus propias normas $y$ procedimiento propio, respetando los derechos humanos de todos los estantes y habitantes del estado Plurinacional de Bolivia.

En suma, se va construyendo un pilar fundamental para dar respuesta a una pluralidad de culturas, que en un punto de coexistencia abre la necesidad de entrar a resolver acontecimientos que por su naturaleza se complementan, donde la Justicia Comunitaria conjuntamente la Justicia Ordinaria trabajan cooperándose mutuamente y coordinan tareas para responder o resolver demandas que se presentan dentro de la jurisdicción indígena, bajo bases jurídicas solidas que protejan los derechos de la sociedad en general y específicamente de la justicia indígena originaria campesina, empero sin desvirtuar la naturaleza de sus usos y costumbres. 
El propósito de este estudio fue realizar una propuesta para la implementación de una norma específica que resguarde los derechos humanos de los Pueblos indígena originarios campesinos de Bolivia a objeto de ajustar nuestra normativa en forma coordinada y coherente para que se adecue a la convención el Convenio 169 sobre Pueblos Indígenas y Tribales en países Independientes.

Para finalizar el estudio estuvo centrado en el punto de vista jurídico, en el ámbito del Derecho Público, específicamente en el área del Derecho Penal y el Derecho Penal Internacional, referente a tratados $y$ convenios internacionales que resguardan los derechos humanos de los Pueblos indígenas originarios campesinos.

\section{Importancia del problema}

Se debe mencionar que en cuanto a las errores de la naturaleza de usos y costumbres en las naciones que aplican la jurisdicción indígena básicamente no cuenta con un código especial que permita establecer y determinar que conductas constituyen en hechos delictivos o no los constituyen, por lo que este aspecto puede hacer que existan excesos y abusos en la aplicación y en el conocer resolver y juzgar dentro del ámbito de la justicia comunitaria, lo cual hace que se vulnere los derechos fundamentales y los derechos humanos.

Sin embargo, revisando la catalogación establecida en el Convenio 169 sobre Pueblos Indígenas y tribales en países independientes, ratificada por Bolivia, el cual entra en vigencia el 11 de diciembre de 1991, en el Art. 3 establece que los Pueblos Indígenas y Tribales, deberán gozar plenamente de los derechos humanos y libertades fundamentales sin obstáculos ni discriminación. Las disposiciones de este Convenio se aplican sin discriminación a los hombres y mujeres de esos pueblos, dando lugar a que exista igualdad de condiciones, en cuanto al área rural y urbana, en consecuencia en nuestra normativa interna, no existe un parámetro normativo especifico que establezca plenamente el reconocimiento de los derechos humanos de los pueblos indígenas originarios campesinos de nuestro país lo que hace que se vulnere los derechos que cada ser humano tiene, ya que nuestra Constitución Política del Estado como también el Pacto de San José de Costa Rica, garantizan, el pleno reconocimiento de los derechos humanos.

La Convención Americana de derechos Humanos, la Constitución Política del Estado, el Convenio 169 sobre Pueblos Indígenas y Tribales en países Independientes, ratificada por Bolivia protege nuestras garantías jurisdiccionales, el debido proceso, el derecho a una defensa amplia e irrestricta y la igualdad de la partes en el proceso, por tal motivo es necesario implementar una norma específica que no vaya en contradicción a lo establecido en $\mathrm{y}$ en mala interpretación en las instituciones de la justicia comunitaria.

Por otro lado, es importante destacar que las naciones y pueblos indígenas originarios campesinos ejercerán su función jurisdiccional y de competencia a través de sus autoridades naturales de acuerdo y en relación a sus pensamientos, usos, costumbres $\mathrm{y}$ sus principios y valores propios de su comunidad, región o país, es por ello, que al establecer la naturaleza de sus usos, costumbres, cultura, se va poder llegar a conocer, cuales son los parámetros para la calificación de una conducta o conductas de las personas de las naciones y que estas no son contrarias a las buenas costumbres y a la normativa legal, con un contenido de relevancia social y su importancia para los Derechos humanos. Entonces ello coadyuvara para que la jurisdicción indígena originaria campesina conozca, resuelvan, casos conflictos problemáticas que históricamente conocieron bajo sus normas y procedimiento propios de cada nación, región o comunidad, por lo que en consecuencia la necesidad de normar la protección de los derechos 
humanos de este sector, para que el estado garantice la efectivizarían de estos derechos.

\section{METODOLOGÍA}

En el desarrollo de este estudio se usaron distinto métodos para el abordaje y tratamiento de las fuentes de información. El método inductivo permitió obtener de la experiencia específica de una o dos comunidades para luego adecuar de manera general la aplicación de la justicia comunitaria en base a sus usos y costumbres, para luego generalizar y ver si su aplicación es igual a otras comunidades. Otro método usado fue el deductivo que se complementa desde lo abstracto general a lo particular de los informes, recuperar aquellos que se originan en medios de comunicación de los comentarios populares y habituales que se tornan en función a la nación difundida de la justicia comunitaria. Aquella realidad que se produce en las regiones que se reconoce la justicia comunitaria, en la que realizan su aplicación estableciendo actas, resoluciones con sanciones que va contribuir al ámbito legal como precedentes de fallos para resolver un caso similar. Con ello va llegar a constituir jurisprudencia en la jurisdicción indígena y en el ordenamiento jurídico penal. La aplicación de la justicia comunitaria en general en las comunidades indígenas en base a sus usos costumbres, tradiciones ancestrales también refleja en casos particulares específicos dentro de una determinada comunidad en la que se determinara la sanción si esta se aplica y quien la ejecuta.

Método Histórico.- Reconstruir episodios anteriores como de la época del incario y colonial.

\section{Métodos específicos}

Método Etnológico.- A partir del estudio de los pueblos y comunidades indígenas originarias campesinas en cuanto a sus usos, costumbres, etc.
Método Exegético.- Se aplicara el análisis de la Legislación Nacional y Comparada.

Método de Análisis y Síntesis.- Se utilizará el análisis de la literatura Jurídica especializada.

Técnicas de Investigación.- Para la presente investigación y posterior conclusión se utilizó las siguientes técnicas:

- Recolección de material bibliográfico (leyes, libros, tratados, periódicos).

\section{RESULTADOS Y DISCUSIÓN}

\section{Analizando la propuesta para normar la Justicia Comunitaria dentro la Justicia Ordinaria}

La propuesta estuvo orientada a crear y fortaleces desde una óptica comparativas teniendo como objeto implementar la justicia comunitaria dentro la justicia ordinaria sin necesidad de desvirtuar la naturaleza de los usos y costumbres de la justicia comunitaria en resguardo de los derechos humanos, orientada a que se respete no solo los derechos fundamentales, sino también la derechos humanos de las personas, puesto que éste derecho se encuentra resguardado y tutelado por nuestra Constitución Política del Estado e Instrumentos Internacionales sobre Derechos Humanos de las personas ratificados por el Estado Plurinacional de Bolivia.

\section{DISCUSIÓN}

\section{Fundamentos}

Existe la necesidad de implementar la justicia comunitaria dentro la justicia ordinaria sin necesidad de desvirtuar la naturaleza de los usos y costumbres de la justicia comunitaria en resguardo de los derechos humanos, ya que no se cuenta con un tratamiento adecuado, en la aplicación de las convenciones sobre derechos humanos, puesto que dicho derecho que toda persona 
tiene, no se encuentra resguardada por una norma específica empero si se encuentra resguardada por la constitución de Boliva, convenios y tratados internacionales, por tal motivo la base jurídica se sustenta en el Artículo 15 de la Constitución Política del Estado Plurinacional de Bolivia, en su parágrafo I, que hace referencia a que todas las personas tienen derecho a la integridad psicológica, que nadie puede sufrir tratos crueles, inhumanos, degradantes o humillante, también se toma en consideración el parágrafo III del citado artículo que señala, que la función primordial del Estado es adoptar las medidas necesarias para prevenir, eliminar y sancionar toda acción u omisión que degrade la condición humana, ya que se ocasiona dolor, sufrimiento físico, psíquico tanto en el ámbito público como privado.

De igual forma se toma en consideración como fundamento la Declaración de las Naciones Unidas sobre los derechos de los pueblos indígenas", esta declaración fue aprobada en la 107 sesión plenaria del 13 de septiembre de 2007, cuyo instrumento jurídico de carácter Internacional fue ratificado por nuestro Estado y en su Artículo 34 de la mencionada declaración tienen amplia conexión y concordancia en relación a los usos y costumbres en la práctica de la Justicia Comunitaria, los mismo refiere que "Articulo 34. "Los pueblos indígenas tienen derecho a promover, desarrollar y mantener sus estructuras institucionales y sus propias costumbres, espiritualidad, tradiciones, procedimientos, practicas, y cuando existan, costumbres o sistemas jurídicos, de conformidad con las normas internacionales de derechos humanos".

También el convenio 169 de la Organización Internacional del Trabajo - OIT, sobre pueblos indígenas y tribales en países independientes, ha establecido en su Art. 8.2. Ha referido textualmente que "Dichos pueblos deberán tener el derecho de conservar sus costumbres o instituciones propias siempre que no sean incompatibles con los derechos fundamentales definidos en el sistema jurídico nacional ni con los derechos humanos internacionales reconocidos. Siempre que sea necesario, deberán establecerse procedimientos para solucionar los conflictos que puedan surgir en la aplicación de este principio.

Y finalmente lo establecido en la Constitución Política del Estado en su Artículo 410 Parágrafo II que establece que "la constitución es la norma suprema del Ordenamiento Jurídico boliviano y goza de primacía frente a cualquier otra disposición normativa. El Bloque de Constitucionalidad está Integrado por los tratados y convenios internacionales en materia de derechos humanos y las normas de derecho comunitario, ratificados por el país..."

\section{Declaración universal de derechos humanos}

Artículo 1.- Todos los seres humanos nacen libres e iguales en dignidad $y$ derechos $y$, dotados como están de razón y conciencia, deben comportarse fraternalmente los unos con los otros.

Artículo 2.- Toda persona tiene los derechos y libertades proclamados en esta Declaración, sin distinción alguna de raza, color, sexo, idioma, religión, opinión política o de cualquier otra índole, origen nacional o social, posición económica, nacimiento o cualquier otra condición.

Artículo 3.- Todo individuo tiene derecho a la vida, a la libertad y a la seguridad de su persona.

Artículo 4.- Nadie estará sometido a esclavitud ni a servidumbre; la esclavitud y la trata de esclavos están prohibidas en todas sus formas.

Artículo 5.- Nadie será sometido a torturas ni a penas o tratos crueles, inhumanos o degradantes.

Artículo 7.- Todos son iguales ante la ley y tienen, sin distinción, derecho a igual protección de la ley. Todos tienen derecho a 
igual protección contra toda discriminación que infrinja esta Declaración y contra toda provocación a tal discriminación.

Es atentatoria e ilícita toda forma de ejercicio que vaya en contra de los derechos de las personas. En tal sentido todo acto que salga de las autoridades indígenas originarias que lesione indebidamente uno de los derechos reconocidos por la declaración de los derechos humanos está ante un supuesto de inobservancia del deber de respeto.

\section{Convenio 169 de la OIT (Organización Internacional del Trabajo)}

El convenio 169 de la Organización Internacional del Trabajo - OIT, sobre pueblos indígenas y tribales en países independientes, fue adoptado por la Conferencia General de este organismo en Ginebra, el 27 de junio de 1989 y de acuerdo con el artículo 33 del mismo, entro en vigor el 05 de septiembre de 1991. El convenio establece derechos indígenas en el uso de los recursos naturales, tierras y autoridades tradicionales, derecho consuetudinario, educación bilingüe y las decisiones sobre las prioridades de las políticas de desarrollo (SIEDER, 1999). Este convenio de carácter multilateral, es un instrumento legal internacional, que es de cumplimiento obligatorio para aquellos estados que han ratificado el referido convenio el cual fue ratificado por Bolivia a través de la Ley No. 1257 de 11 de julio de 1991, por lo que en virtud a ello los estados ratificantes $\mathrm{y}$ en particular Bolivia debe respetar y proteger implementar políticas para defender los derechos de los pueblos, tribales originarios indígenas campesinos.

A manera de antecedente diríamos que la Organización Internacional del Trabajo es una institución de la ONU, que tiene el objetivo de contribuir a la creación de una mayor justicia social mediante la mejora de la legislación en materia de trabajo. Esta institución surgió de la conferencia de Montreal 1946, como reconstrucción del Buro Internacional del trabajo (BIT) creado en 1919 por el tratado de Versalles.

Es así que el convenio referido, en relación a los Usos y Costumbres y la Justicia Comunitaria indica:

Art. 8 1. Al aplicar la legislación nacional a los pueblos interesados, deberán tomarse debidamente en consideración sus costumbres o su derecho consuetudinario.

2. Dichos pueblos deberán tener el derecho de conservar sus costumbres o instituciones propias siempre que no sean incompatibles con los derechos fundamentales definidos en el sistema jurídico nacional ni con los derechos humanos internacionales reconocidos. Siempre que sea necesario, deberán establecerse procedimientos para solucionar los conflictos que puedan surgir en la aplicación de este principio.

Del análisis del convenio se puede colegir que todos los estados signatarios $\mathrm{y}$ suscribientes además de ratificar mediante normativa legal tienen la obligación de reconocer los derechos de las naciones indígenas originarias, tribales campesinas. Para ello los estados deben promover políticas de respeto y protección para cumplir el referido convenio. Sin embargo se estipula un límite que es fundamental, al aplicar las costumbres no deben conculcar ni violar los derechos fundamentales y el derecho a la vida, es decir no aplicar el linchamiento o pena de muerte, que se produce en los países de Latinoamérica y en particular en nuestro a título de la Justicia comunitaria que no corresponde, puesto que atenta contra el valor supremo que es la vida y que nadie tiene derecho a quitar. Y lo que es muy destacable en nuestra patria se creó la normativa legal que es la ley $\mathrm{N}^{\circ} 073$ de 29 de diciembre de 2010 de deslinde jurisdiccional que principalmente dispone el respeto a los Derechos Fundamentales y garantías constitucionales y de forma taxativa prohíbe 
el linchamiento y la pena de muerte.

\section{Declaración de las Naciones Unidas sobre los derechos de los Pueblos Indígenas}

La Asamblea General de las Naciones Unidas aprobó la "Declaración de las Naciones Unidas sobre los derechos de los pueblos indígenas", esta declaración fue aprobada en la 107 sesión plenaria del 13 de septiembre de 2007, cuyo instrumento jurídico de carácter Internacional fue ratificado por nuestro Estado, mediante normativa legal. En consecuencia todos estos tratados y declaraciones vienen a formar parte del bloque constitucional a favor de los pueblos indígenas que debe ser cumplido como una ley. En ese entendido que dentro del contexto de los derechos culturales de los pueblos indígenas el artículo 3 de la declaración refiere:

"Los pueblos indígenas tienen derecho a la libre determinación. En virtud de ese derecho determinan libremente su condición política y persiguen libremente su desarrollo económico, social y cultural".

De la misma forma los artículos 5 y 34 de la mencionada declaración tienen amplia conexión y concordancia en relación a los usos y costumbres en la práctica de la Justicia Comunitaria, los mismos que paso a glosar:

Artículo 5. "Los pueblos indígenas tienen derecho a conservar y reforzar sus propias instituciones políticas, jurídicas, económicas, sociales y culturales".

Artículo 34. "Los pueblos indígenas tienen derecho a promover, desarrollar $y$ mantener sus estructuras institucionales $y$ sus propias costumbres, espiritualidad, tradiciones, procedimientos, practicas, $y$ cuando existan, costumbres o sistemas jurídicos, de conformidad con las normas internacionales de derechos humanos".

Conforme al análisis y conclusión que se llega en relación a la declaración de las naciones unidas establece los derechos de los pueblos indígenas como el de la libre determinación, consagra sus instituciones prácticas, procedimientos y sus costumbres, empero dispone un límite que es fundamental que debe estar conforme a las normas internacionales sobre los derechos humanos, vale decir que dentro de su prácticas y la aplicación de la justicia comunitaria, como una forma de resolución de sus conflictos y problemas, deben respetar el derecho a la vida y no aplicar la pena de muerte ni el linchamiento, puesto que ello implica que van en contra de la referida declaración de la ONU y va en contra de los derechos humanos.

\section{Niveles de coordinación entre Justicia Estatal y Justicia Comunitaria}

De acuerdo con la escritora Fajardo (1999), los ejes para establecer pautas de coordinación entre el Derecho Indígena y el estatal, deben resolver, entre otros, temas el establecimiento de criterios y reglas para definir y resolver los conflictos de competencia, definición de los ámbitos de intervención de la justicia indígena, al igual que definir los llamados límites o "fronteras", por ello, es menester construir mecanismos estables de coordinación con los respectivos Estados que den cuenta de asuntos esenciales como:

- Los efectos institucionales de las decisiones judiciales que tomen las autoridades indígenas, es decir, el acatamiento por parte de los agentes y/o funcionarios del estado mediante, por ejemplo, el carácter de cosa juzgada y, en consecuencia, la imposibilidad para el sujeto étnico de ser juzgado dos veces por el mismo delito, como muchas veces sucede en la práctica.

La colaboración de parte de las autoridades estatales para hacer cumplir las determinaciones asumidas por estas autoridades, especialmente en aquellos casos complejos que superan la capacidad efectiva 
de las comunidades o se ubiquen por fuera del ámbito territorial indígena.

- El desarrollo de procesos investigativos que por sus características requieren de cierto apoyo técnico, logístico y tecnológico.

- La implementación de una política carcelaria flexible que se adecue a los distintos pensamientos étnicos en materia de encierro, castigo, rehabilitación y resocialización.

- Una real asignación de presupuesto y una clara participación en la decisión de los recursos de la administración de justicia, máxime si se tiene en cuenta el aporte de la justicia indígena en lo que concierne a la descongestión de los despachos judiciales y la necesidad de una infraestructura mínima para que las autoridades sean operativas en materia de justicia.

- Acceso a información como también un sistema de registro compatible entre lo indígena y lo estatal.

En el texto criterios y pautas para la coordinación entre el derecho indígena y el derecho estatal (Fajardo, 1999) se establecen los siguientes elementos a tener en cuenta en la coordinación:

1. Competencia material;

2. Competencia territorial;

3. Competencia personal;

4. Competencia temporal entre ambos sistemas;

5. Descriminalización del derecho y la justicia indígenas;

6. Mecanismos para el respeto de actos jurídicos del derecho indígena;

7. Mecanismos para el respeto de decisiones jurisdiccionales de la justicia indígena;

8. Remisión de casos o situaciones al derecho indígena;
9. Fortalecimiento de autoridades indígenas y pautas de relación con autoridades estatales;

10. Mecanismos de colaboración y apoyo entre sistemas;

11. Procedimientos para resolver denuncias por presunta violación de derechos humanos por parte del derecho indígena.

De lo anteriormente referido podemos concluir señalando que tanto la justicia comunitaria como la justicia ordinaria deben aportar esfuerzos para coordinar $y$ compatibilizar entre ambos para resolver los conflictos que se les plantea, respetando los derechos individuales y colectivos, para lograr una coexistencia de tranquilidad, sin vulnerar derechos constitucionales y tampoco vulnerar derechos comunales colectivos.

\section{Nivel de cooperación entre Justicia Comunitaria y Justicia Ordinaria}

Dado que las demandas indígenas se han enfatizado y los reclamos específicos de las comunidades en relación a la obtención de territorios, al desarrollo étnico y cultural, al desarrollo económico auto gestionado y a la consecución de un orden jurídico que esté en manos de sus propias autoridades, han tomado una dimensión propia es que se justifica la necesidad de la existencia de los niveles de coordinación entre los diferentes sistemas jurídicos.

Siguiendo tres criterios desarrollados por la antropología en los que se entiende que sistemas jurídicos puedan: sustituirse, competir y complementarse entre sí. Puede encontrarse maneras de resolver los conflictos que se presente por problemas de competencias y de jurisdicciones. En este caso de acuerdo a las teorías de sistemas, la contradicción entre normas tiende a anular una de las normas en conflicto, mientras que el conflicto entre principios prevalece el valor mayor protegido (principio de 
proporcionalidad). Este nivel de coordinación se encuentra en dos niveles que se distinguen nítidamente:

\section{El nivel normativo; \\ 2. El nivel factico.}

En el nivel normativo, la pluralidad jurídica está reconocida constitucionalmente en diferentes países latinoamericanos. Podría definirse como la existencia simultanea dentro del mismo espacio de un Estado de diversos sistemas de regulación social y resolución de conflictos, basados en cuestiones culturales, étnicas, raciales, ocupacionales, histórica, económica, ideológica, geográfica, política, o por la diversa ubicación en la conformación de la estructura social que ocupan los actores sociales. Es así que se busca el respeto a la diversidad buscando vías de comunicación entre el derecho indígena y el derecho oficial.

En el nivel factico, se reconoce la existencia de diversidad, aceptando los derechos reclamados por los pueblos indígenas. Esto implica la coexistencia de cosmovisiones distintas, de prácticas diversas, de culturas diferentes y lo que es crucial en el análisis de una justicia diferenciada: La existencia de intereses en conflicto. Es la propia realidad la que impulsa la necesidad de regulación de una convivencia que en muchos aspectos es forzada, porque como ya se ha explicado, esta interrelación no está exenta de tensiones, y sólo un tratamiento despojado de dobleces será factible alcanzar; fundando en el respeto y en la tolerancia de otros modos de vida.

De lo referido precedentemente se concluye que es necesario que exista aspectos de compatibilización para una coexistencia entre dos sistemas jurídicos dentro de nuestro país con la finalidad de establecer mecanismos de cooperación y coordinación encontrando un punto de equilibrio entre ambos sin vulnerar los derechos colectivos, étnicos, culturales y sin vulnerar los derechos y garantías constitucionales individuales que tiene todo ser humano. (Ariza y otros, 2007)

Jurisprudencia Constitucional del Tribunal Constitucional Plurinacional De Bolivia No. 0300/2012-R De 18 De Junio De 2012, Sobre Pluralismo Juridico (Supone igualdad jerárquica de la jurisdicción indígena originaria campesina con la ordinaria $y$ viceversa)

En el ámbito descrito, el reconocimiento transversal de los derechos de las naciones y pueblos indígena originario campesinos, abarca también al campo jurídico, pues existe un reconocimiento del pluralismo jurídico igualitario que deriva del reconocimiento constitucional de la igual jerarquía de la jurisdicción indígena originaria campesina con la ordinaria (art. 179.II de la CPE) y del sistema jurídico ordinario con el sistema indígena originario campesino.

La jurisdicción indígena originaria campesina, de acuerdo al art. 179 de la CPE, forma parte del órgano judicial, haciendo efectivo el derecho de las naciones y pueblos indígena originario campesinos a que su instituciones sean parte de la estructura general del Estado (art. 30.II.5 de la CPE) y, en ese ámbito, al gozar de igual jerarquía que la jurisdicción ordinaria, esta no puede revisar las resoluciones pronunciadas por la jurisdicción indígena originara campesina y tampoco está de aquella; es más, toda autoridad pública o persona debe acatar las decisiones de esta jurisdicción, pudiendo las autoridades solicitar el apoyo de los órganos competentes del Estado (art. 192 de la CPE)".

\section{CONCLUSIONES}

Conforme la sociedad fue evolucionando así también fueron progresando los derechos de toda persona, pues así también la Justicia Comunitaria al tener sus propias normas, procedimientos y derecho propio esto de acuerdo a su naturaleza, cultura, usos y 
costumbres, que ayudan a resolver problemas, conflictos o controversias que salen de las relaciones sociales de una comunidad indígena, garantizadas por la Constitución Política del Estado de Bolivia, empero en muchos casos estas resoluciones que emite la justicia indígena como forma de resolver un conflicto, son contrarios a la constitución especialmente en materia de derechos humanos, existe desconocimiento de la Constitución Política del Estado, la cual establece límites constitucionales a la justicia indígena originaria campesina, para que los derechos individuales sean protegidos cuando se tomen decisiones que si bien tienen un reconocimiento constitucional que le otorga fortaleza jurídica igualitaria a la justicia ordinaria, este debe ejercerse dentro del marco de las normas constitucionales y tratados y convenios internacionales con el único objetivo de lograr la paz social, y poder establecer bases normativas para normar la justicia comunitaria dentro la justicia ordinaria sin necesidad de desvirtuar la naturaleza de los usos y costumbres de la justicia comunitaria en resguardo de los derechos humanos.

En cuanto a sus normas propias, se ha podido observar que tiene una función de prevención y se aplica para solucionar problemas, conflictos o disputas que surgen de las interrelaciones cotidianas, sin embargo se sigue utilizando la triologia "ama khella, ama llulla, ama suwa" (no ser flojo, no ser mentiroso y no ser ladrón) que denotan normas de conducta que han sido heredados de antepasados convirtiéndose en normas de conducta social y normas consuetudinarias y en cuanto a su procedimiento, se ha podido detectar que aplican el sistema oral, la denuncia por un hecho que afectan los usos y buenas costumbres de la comunidad es de manera oral, el sistema de administrar justicia es distinto pero existe similitud en cuanto al sistema de autoridades jerarquizada en función al cargo determinado, sin embargo en la resolución de sus conflictos a lo largo de la historia no se ha enmarcado en el respeto incólume de los derechos humanos, porque esta forma de administrar justicia solo llega a responder los intereses de la comunidad o sus representantes, vulnerando incluso los derechos de la colectividad y los derechos individuales en desprotección de los derechos humanos.

Por otra parte el Estado boliviano está obligado de velar por los intereses de los ciudadanos en el marco de la aplicación de la nueva Constitución Política del Estado que fue promulgada y aprobada el año 2009, la cual incorpora derechos humanos de las personas, que también están regulados por Tratados y Convenios Internacionales reflejados en nuestro ordenamiento jurídico en la Declaración Universal de los Derechos Humanos, la Declaración de las Naciones Unidas y la Convención Americana sobre derechos Humanos "Pacto de San José de Costa Rica", por lo que la Justicia Comunitaria y la Justicia Ordinaria se enfrentan a un gran reto de diálogo intercultural en el escenario de la justicia, lo que implica un esfuerzo reciproco a todo nivel para hacer cumplir las determinaciones tomadas por las autoridades indígenas, especialmente en aquellos casos complejos que superan la capacidad efectiva de la justicia indígena o que se ubiquen fuera de la jurisdicción indígena, hhoy en día se ha presentado varios problemas por el tema de territorio, desarrollo económico, cumplimiento de sus decisiones etc., donde la Justicia Comunitaria se ha encontrado con pocas herramientas para dar solución, por lo que se ha visto en la necesidad de entrar o tocar las puertas de la Justicia Ordinaria para dar solución bajo la denominación de cooperación y coordinación con lineamiento de bases jurídicas para abarcar esta situación.

También se concluye que la legislación comparada toma en consideración la jurisdicción indígena originaria campesina que se encuentran reconocidas en sus 
constituciones como ser México, Venezuela, Ecuador, Colombia y Guatemala, así como también se encuentra reconocida en nuestra Constitución, en nuestro caso dándole jerarquía igualitaria con la justicia ordinaria y que al mismo tiempo, esta norma fundamental limita en cuando a su administración de justicia para la no vulneración de los derechos humanos y garantías constitucionales, es en este entendido que se debe tener presente un punto de convergencia que no vulnere derechos colectivos, socioculturales con sus principios, normas y procedimientos propios adquiridos ancestralmente, respetando los derechos Humanos como los usos y costumbres de los Pueblos Indígena originario Campesinos.

\section{REFERENCIAS}

Ariza Rosembert, Ossio, L. Gutiérrez, G. Obra Justicia Ordinaria y Justicia Consuetudinaria, impresión Central Grafica s.r.l. 2007, Fundación Konrad Adenaur, págs. $10,11,12,13,14,14,16,17$, 18 al 35, 78,79,80,81.

Fajardo, R. Y. (1999). Pautas de coordinación entre el derecho indígena y el derecho estatal. Fundación Myrna Mack.
Stavenhagen, R. (2004). Derecho internacional y derechos indígenas. Derechos Humanos y Pueblos Indígenas: tendencias internacionales y contexto chileno, 23.

\section{Normativas legales}

Constitución Política del Estado Ley N¹615 de 6 de febrero de 1995, Compilación de Leyes Penales págs. 5 y 54, Ediciones El Original 2008.

Constitución Política del Estado promulgada 2009, ed. U.P.S. S.r.l., 2009.

Jurisprudencia Constitucional del Tribunal Constitucional Plurinacional De Bolivia No. 0300/2012-R De 18 De Junio De 2012, Sobre Pluralismo Jurídico

\section{Tratados y convenios internacionales}

de Derechos Humanos, D. U. (1948). Declaración Universal de los Derechos humanos. Declaración Universal de los derechos Humanos, (pág. 5).

El Convenio 169 de la OIT (Organización Internacional del Trabajo)

Naciones Unidas. (2007). Declaración de las Naciones Unidas sobre los derechos de los pueblos indígenas.

HUMANOS, C. A. D. D. (1969). Pacto de San José da Costa Rica. San José da Costa Rica, 22 